\title{
Clinical significance of maxillary sinus hypoplasia in dentistry: A CBCT study
}

\section{Znaczenie kliniczne niedorozwoju zatoki szczękowej w stomatologii - badanie w tomografii stożkowej}

\author{
Numan Dedeoğlu ${ }^{A, B, D, E}$, Suayip Burak Duman ${ }^{B, D-F}$ \\ Department of Oral and Maxillofacial Radiology, Faculty of Dentistry, İönü University, Malatya, Turkey \\ A - research concept and design; B - collection and/or assembly of data; $C$ - data analysis and interpretation; \\ $D$ - writing the article; $E$ - critical revision of the article; $F$ - final approval of the article
}

\section{Address for correspondence \\ Suayip Burak Duman \\ E-mail: suayipburakduman@gmail.com}

\section{Funding sources}

None declared

Conflict of interest

None declared

Received on July 31, 2019

Reviewed on 0ctober 21, 2019

Accepted on December 2, 2019

Published online on June 29, 2020

Cite as

Dedeoğlu N, Duman SB. Clinical significance of maxillary sinus hypoplasia in dentistry: A CBCT study. Dent Med Probl. 2020;57(2):149-156. doi:10.17219/dmp/114982

DOI

$10.17219 / \mathrm{dmp} / 114982$

Copyright

๑ 2020 by Wroclaw Medical University

This is an article distributed under the terms of the

Creative Commons Attribution 3.0 Unported License (CC BY 3.0)

(https://creativecommons.org/licenses/by/3.0/).

\begin{abstract}
Background. The anatomy of the maxillary sinus is especially important for dentists due to the close proximity of the sinus to the maxillary posterior teeth.

Objectives. The aim of the present study was to investigate the frequency of maxillary sinus pathology, anatomical variations, and the relationship between the tooth roots and the maxillary sinus by comparing a group with maxillary sinus hypoplasia (MSH) and a control group using cone-beam computed tomography (CBCT).

Material and methods. In the study, 69 CBCT images of 50 patients with MSH and 84 CBCT images of 49 patients without MSH were evaluated for pathology, and the presence of an accessory ostium, a septum and Haller cells in each maxillary sinus.

Results. The coincidence of pathology with MSH was 29\%, and with non-hypoplastic maxillary sinuses it was $44 \%$ ( $p=0.055)$. An accessory ostium was found in $14.5 \%$ of scans with MSH and in $39.3 \%$ of those without MSH ( $p=0.001)$. Haller cells were found in $2.9 \%$ of the MSH cases, whereas their incidence in the control group was $23.8 \%(p=0.000)$. The occurrence of a sinus septum was at the level of $4.3 \%$ in the group with MSH and $23.8 \%$ in the group without MSH ( $p=0.001$ ).

Conclusions. The incidence of the relationship between the sinus wall and the posterior root apices was found smaller in the dentulous MSH patients. Also, the distance between the root apices and the sinus wall was longer in the dentulous MSH patients, and the vertical and horizontal alveolar bone was larger in the posteriorly edentulous MSH patients.
\end{abstract}

Key words: dental implant, endodontic treatment, alveolar crest, maxillary sinus hypoplasia

Słowa kluczowe: implant stomatologiczny, leczenie endodontyczne, grzebień zębodołowy, niedorozwój zatoki szzzękowej 


\section{Introduction}

The anatomy of the maxillary sinus is especially important for dentists because of the close proximity of the sinus to the maxillary posterior teeth. In some cases, maxillary sinusitis may have an odontogenic cause due to the close relationship between the sinus wall and the root apices of the maxillary posterior teeth, which can lead to some impairment, such as periodontal and periapical lesions and tooth extractions. ${ }^{1}$

The maxillary sinus, the largest paranasal sinus, begins to develop in the $10^{\text {th }}-12^{\text {th }}$ week of gestation and the cavity becomes identifiable at 16 weeks of gestation. At birth, the volume of the maxillary sinus is $6-8 \mathrm{~mm}^{3}$, and it increases with the the growth of the nasal cavity, the infraorbital wall, the alveolar process, and the zygomatic process. The volume of the maxillary antrum increases vertically and laterally by $2 \mathrm{~mm}$ per year and by $3 \mathrm{~mm}$ per year anteroposteriorly. The final pneumatization of the maxillary sinus occurs principally in an inferior direction after the eruption of the maxillary teeth. The adult size is reached at the age of $15-18.2,3$

Maxillary sinus hypoplasia (MSH) is a relatively rare clinical condition, ${ }^{2}$ not particularly well-known among dentists and oral surgeons. Maxillary sinus hypoplasia can be congenital or acquired (due to surgery or trauma). ${ }^{4}$ Most cases of MSH do not cause any symptoms in patients, who are unaware of their condition, and it is generally diagnosed incidentally. ${ }^{2}$

Currently, cone-beam computed tomography (CBCT) is widely used in the diagnostic imaging of the head and neck region, although it is a relatively new radiological technique. ${ }^{5}$ Cone-beam computed tomography enables three-dimensional (3D) data acquisition, followed by image reconstruction, display, and interpretation. The CBCT scanning is rapid and delivers only low doses of radiation; its modality is ideal for imaging children and claustrophobic adults. ${ }^{6}$ Cone-beam computed tomography has been shown to be at least as good as computed tomography (CT) when used to examine bone structures (e.g., the skull base, the paranasal sinuses and the temporal bone) and pathologies in the oral and maxillofacial regions. ${ }^{7,8}$ Even though CBCT is commonly used by dentists, otolaryngologists also favor this technique because of the good image quality it provides. ${ }^{9}$

The aim of this study was to investigate the frequency of maxillary sinus pathology, anatomical variations, and the relationship between the tooth roots and the maxillary sinus by comparing the CBCT records of patients from the group with $\mathrm{MSH}$ and from the group without $\mathrm{MSH}$.

\section{Material and methods}

In the study, $69 \mathrm{CBCT}$ images of 50 patients with MSH and 84 CBCT images of 49 patients without MSH were used. In total, 153 maxillary sinuses of 99 patients were evaluated, of which 88 had teeth in the neighboring dental arch, whereas 65 dental arches adjacent to the maxillary sinuses were edentulous. Forty-five of the 88 sinuses with the posterior maxillary teeth were hypoplastic sinuses, whereas of the 65 posteriorly edentulous maxillary sinuses, 24 were hypoplastic. The CBCT records of the posteriorly edentulous patients belonged to people who had been scanned for pre-surgical implant evaluation. The age of the patients who participated in the study was between 20 and 90 years.

All the walls of the maxillary sinus and the teeth near the base of the sinus wall were determined as the work area of each half-jaw. A maxillary sinus with half or less of the maximum horizontal or vertical linear dimension of the orbit on the same side was defined as hypoplastic (Fig. 1). ${ }^{10}$

The exclusion criteria were the following: dental loss and deficiency in the process area; an implant or a bone graft; large pathologies disrupting the anatomy of the process area; planned surgery in the maxillary sinus; bone metabolism diseases; or third molars with no apical foramina.

The CBCT images obtained from the Department of Oral and Maxillofacial Radiology at the Faculty of Dentistry of İnönü University in Malatya, Turkey, were evaluated retrospectively by an experienced oral radiologist (N.D.). This study was approved by the İnönü University Scientific Research and Publication Ethics Committee (approval No. 2019/2-1 as of January 22, 2019).

The images evaluated in the study were performed using the NewTom 5G CBCT device (NewTom,Verona, Italy) (standard $110 \mathrm{kVp}, 20 \mathrm{~mA}$ maximum). The scanning time was $18 \mathrm{~s}$, and a display area of $18 \mathrm{~cm} \times 16 \mathrm{~cm}$ or $15 \mathrm{~cm} \times 12 \mathrm{~cm}$ (field of view - FOV) was used. The voxel values of the images were $0.3 \mathrm{~mm}, 0.25 \mathrm{~mm}$ and $0.2 \mathrm{~mm}$.

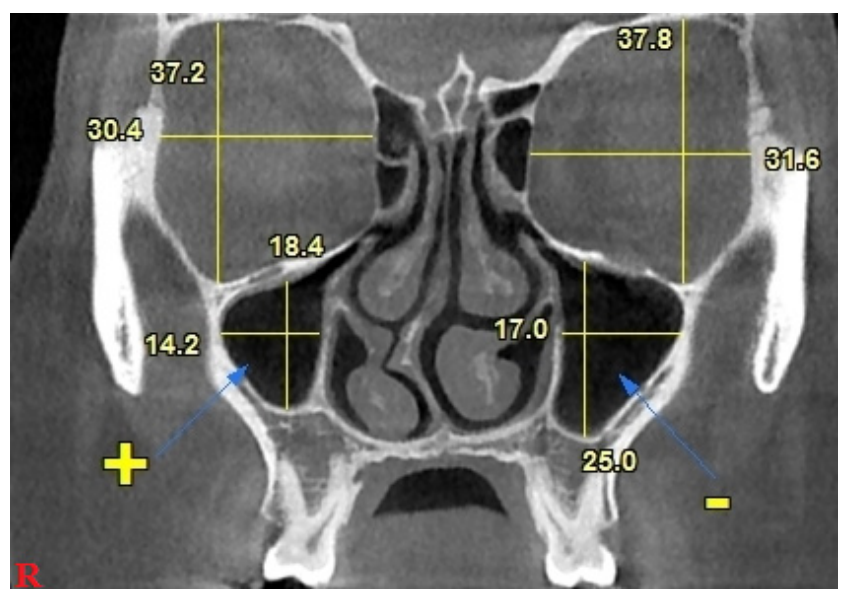

Fig. 1. The right maxillary sinus is considered hypoplastic, since the maximum maxillary dimension is less than half the maximum orbital dimension - 18.4< 18.6 (37.2 / 2); the left maxillary sinus is not regarded as hypoplastic, as the maximum maxillary dimension is more than half the maximum orbital dimension $-25>18.9(37.8 / 2)$ 
The CBCT images were evaluated using the NNT (New NewTom) software. All images reviewing coronal sections, pathology and the presence of accessory ostia, septa and Haller cells in each maxillary sinus were evaluated and recorded with regard to the groups with and without MSH (Fig. 2). We also evaluated whether the tooth root apices were associated with the maxillary sinus (Fig. 3A,3B).

In the maxillary sinuses with the posterior teeth, the distance between the closest tooth root to the maxillary sinus wall and the sinus was measured linearly along the tooth root-sinus floor in the groups with and without hypoplasia, respectively (Fig. 3C,3D). When the tooth root penetrated the sinus wall, the distance from the sinus wall to the root apices was accepted as 0 (Fig. 3E).

In the maxillary sinuses without the posterior teeth, the narrowest alveolar crest width, along with the vertical length where the distance between the alveolar crest and the maxillary sinus was the smallest, was measured linearly (Fig. 4).

The data obtained in this study were analyzed with the IBM SPSS Statistics for Windows software, v. 22 (IBM Corp., Armonk, USA). When investigating the normal distribution of variables, the Shapiro-Wilk test was utilized due to the number of units. When examining the differences between the groups, the Mann-Whitney $U$-test was chosen, as the variables were not normally distributed. The $X^{2}$ test was used when examining the relationships between the groups with nominal variables. When interpreting the results, the level of significance was set at 0.05 . The kappa value for the inter-observer agreement was calculated.

\section{Results}

In this study, the mean age of the population of $99 \mathrm{pa}-$ tients - 43 men (43.3\%) and 56 women $(56.7 \%)$ - was found to be $42.25 \pm 14.27$ years (min: 20 ; $\max$ : 90$)$ ). The mean age of the patients with MSH was 41.1 years (min: 20; max: 90) and the mean age of the patients without MSH was 43.53 years (min: 21; $\max : 74)$ ). There were 50 patients with $\mathrm{MSH}$, including 22 men (44\%) and 28 women (56\%). There were 49 people without $\mathrm{MSH}$ - 21 men (42.9\%) and 28 women (57.1\%). In the study, 153 maxillary sinuses of 99 patients were evaluated. Eighty-four of these 153 sinuses belonged to female patients, whereas 69 belonged to male patients.
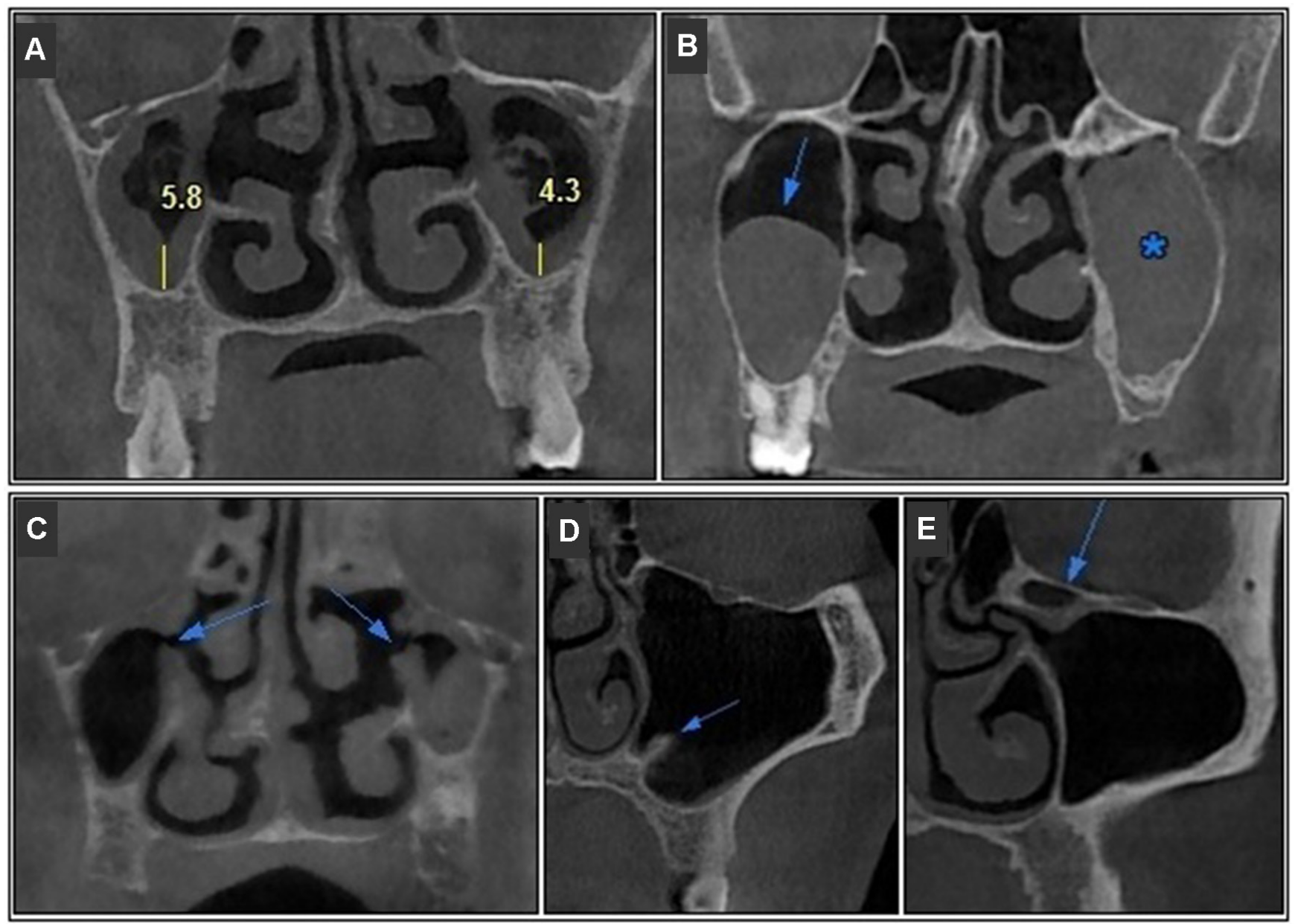

Fig. 2. A - mucosal thickening (>3 mm); B - mucosal retention cyst (arrow) and polypoid lesion (asterisk); C - accessory ostium; D - septum; E - Haller cells 

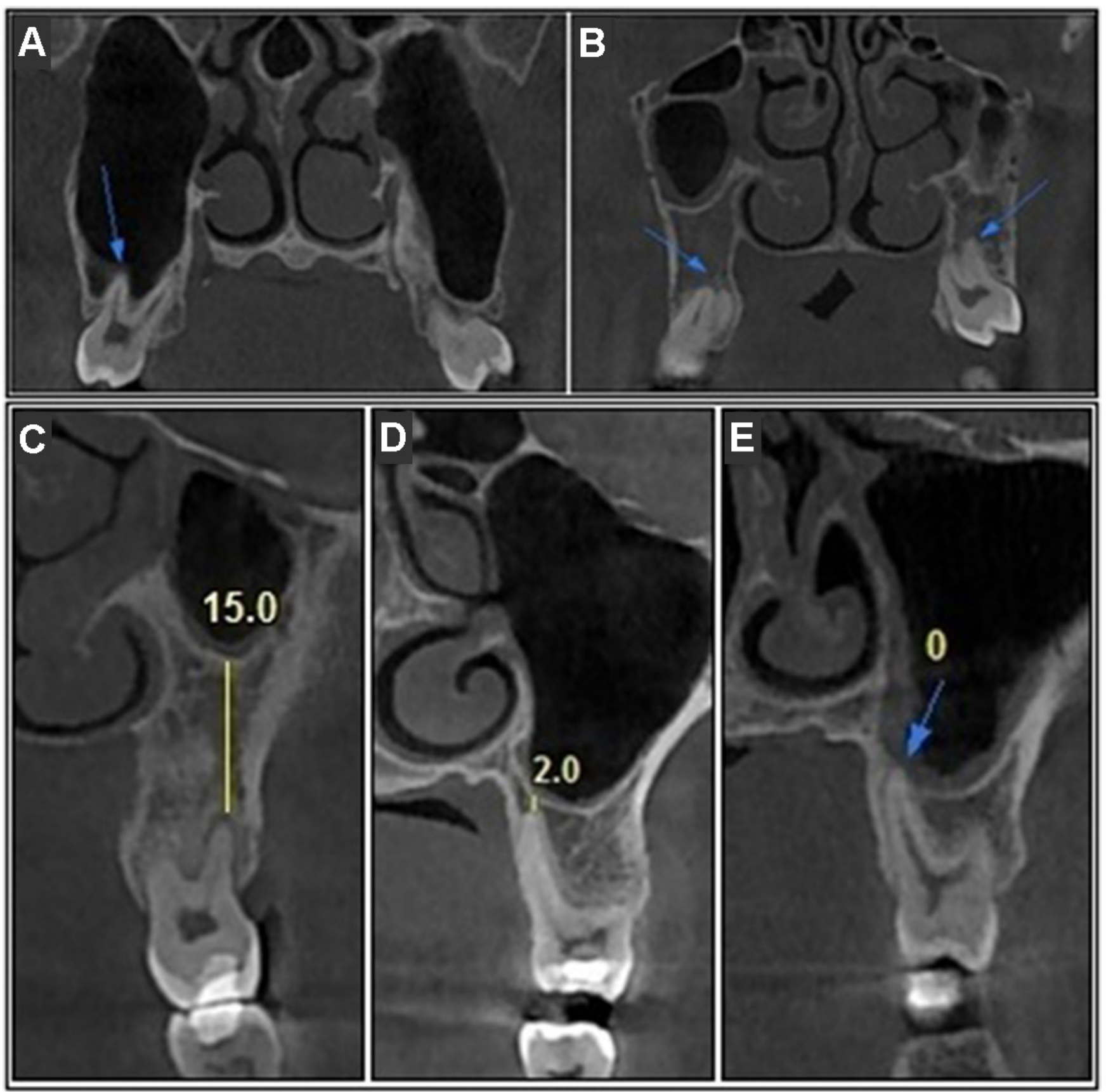

Fig. 3. A - tooth roots associated with the maxillary sinus; B - unbound; C,D - distance between the tooth root apices and the sinus wall; $E$ - tooth root penetrating the sinus wall

A total of 88 maxillary sinuses (45 hypoplastic and 43 non-hypoplastic) belonging to 56 patients with the posterior teeth (31 women and 25 men) were evaluated. Twenty-three of the 45 hypoplastic maxillary sinuses with the posterior teeth belonged to female patients, whereas 22 of them belonged to male patients. Twenty-five of the 43 non-hypoplastic maxillary sinuses with the posterior teeth belonged to female patients and 18 of them to male patients (Table 1).

A total of 65 maxillary sinuses (24 hypoplastic and 41 non-hypoplastic) belonging to 43 posteriorly edentulous patients ( 25 women and 18 men) were evaluated. Thirteen of the 24 hypoplastic maxillary sinuses with
Table 1. Prevelance of maxillary sinus hypoplasia (MSH) by gender

\begin{tabular}{|l|c|c|c|}
\multicolumn{1}{|c|}{ Study group } & Gender & $\begin{array}{c}\text { Patients } \\
n(\%)\end{array}$ & $\begin{array}{c}\text { Maxillary sinuses } \\
n(\%)\end{array}$ \\
\hline $\begin{array}{l}\text { Dentulous } \\
\text { hypoplastic sinus }\end{array}$ & female & $17(17.17)$ & $23(15.03)$ \\
$\begin{array}{l}\text { Dentulous } \\
\text { non-hypoplastic sinus }\end{array}$ & male & $15(15.15)$ & $22(14.38)$ \\
Edentulous & male & $10(10.10)$ & $18(11.76)$ \\
hypoplastic sinus & female & $11(11.11)$ & $13(8.50)$ \\
Edentulous & male & $7(7.07)$ & $11(7.19)$ \\
non-hypoplastic sinus & female & $14(14.14)$ & $23(15.03)$ \\
\multicolumn{1}{c}{ Total $N$} & male & $11(11.11)$ & $18(11.76)$ \\
\hline
\end{tabular}


Fig. 4. Horizontal and vertical alveolar crest dimensions

A - hypolastic sinus;

B - non-hypoplastic sinus.
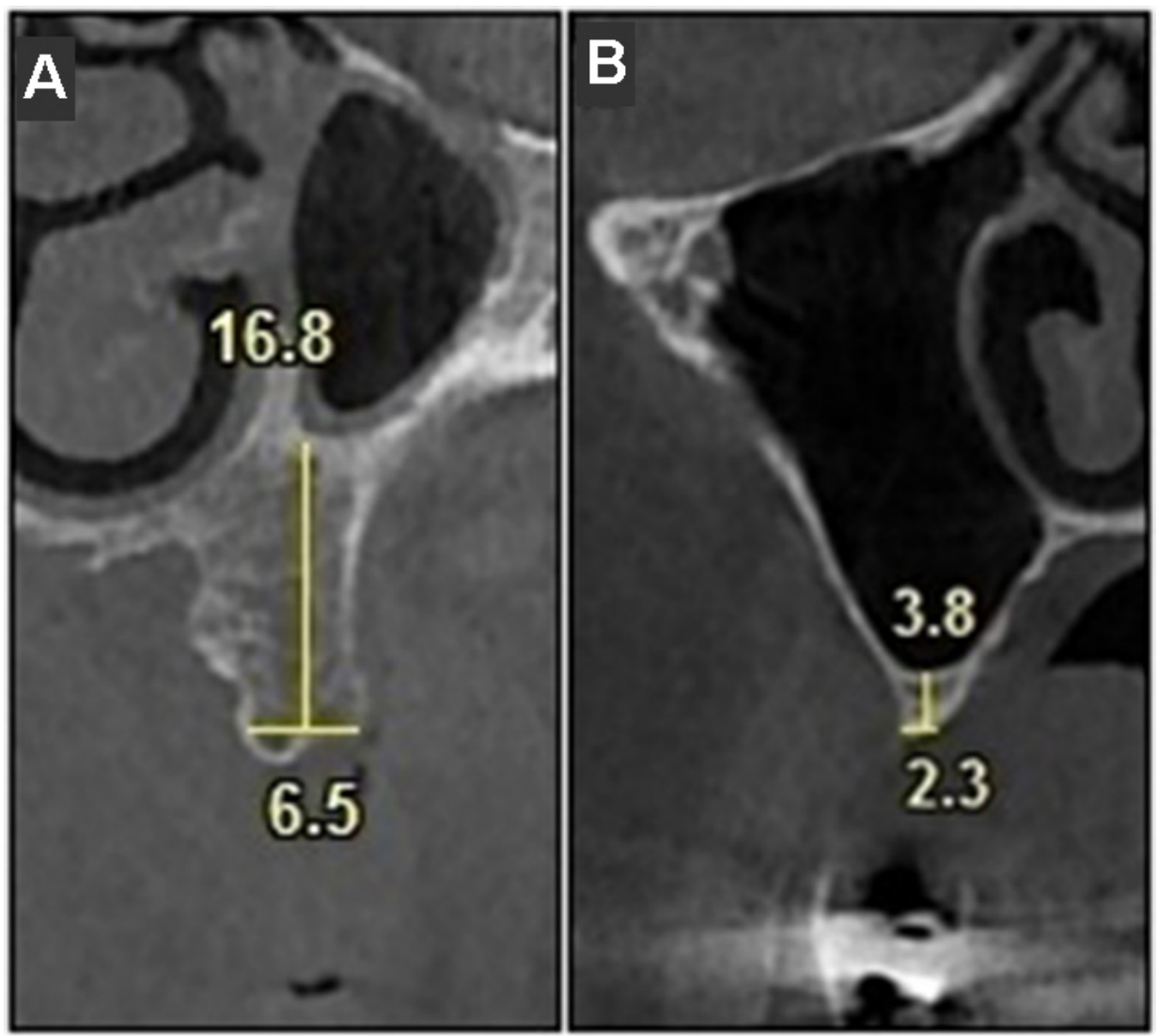

posteriorly edentulous jaws belonged to female patients, whereas 11 of them belonged to male patients. Twentythree of the 41 non-hypoplastic maxillary sinuses with posteriorly edentulous jaws belonged to female patients and 18 of them to male patients (Table 1 ).

\section{Comparison of the group with maxillary sinus hypoplasia and the group without maxillary sinus hypoplasia in terms of anatomic variations}

The incidence of pathology in the group with MSH was $29 \%$, whereas it was $44 \%$ in the group with non-hypoplastic maxillary sinuses. No statistically significant difference was found when comparing these 2 groups (Table 2).

In the group with $\mathrm{MSH}$, the incidence of an accessory ostium was $14.5 \%$, whereas $39.3 \%$ of the group without $\mathrm{MSH}$ had an accessory ostium. A statistically significant difference was found when comparing these 2 groups (Table 2).

Haller cells were found in $2.9 \%$ of the group with MSH, whereas $23.8 \%$ of the scans without MSH displayed Haller cells. This difference was statistically significant (Table 2).

The presence of a maxillary sinus septum was observed in $4.3 \%$ of the group with $\mathrm{MSH}$, whereas it was $23.8 \%$ in the group without MSH. When these 2 groups were compared, a statistically significant difference was found (Table 2).
Table 2. Statistical comparison of pathology, anatomic variations and the tooth root-sinus relationship in hypoplastic and non-hypoplastic maxillary sinuses

\begin{tabular}{|l|c|cc|}
$\begin{array}{l}\text { Pathology, anatomical } \\
\text { variations, root-sinus } \\
\text { relationship }\end{array}$ & $\begin{array}{c}\text { Hypoplastic } \\
\text { maxillary sinuses } \\
n(\%)\end{array}$ & $\begin{array}{c}\text { Non-hypoplastic } \\
\text { maxillary sinuses } \\
n(\%)\end{array}$ & $p$-value \\
\hline $\begin{array}{l}\text { Pathology }^{\text {a }} \\
\text { Accessory ostium }^{\text {a }}\end{array}$ & $20(29)$ & $37(44)$ & 0.055 \\
Haller cells $^{\mathrm{a}}$ & $10(14.5)$ & $33(39.3)$ & $0.001^{*}$ \\
Septum $^{\mathrm{a}}$ & $2(2.9)$ & $20(23.8)$ & $0.000^{*}$ \\
Root-sinus relationship $^{\mathrm{b}}$ & $3(4.3)$ & $20(23.8)$ & $0.001^{*}$ \\
\hline
\end{tabular}

a comparison between all maxillary sinuses; ${ }^{b}$ comparison between dentulous maxillary sinuses; ${ }^{*}$ statistically significant; $x^{2}$ test.

\section{Comparison of the group with maxillary sinus hypoplasia with the posterior teeth and the group without maxillary sinus hypoplasia with the posterior teeth}

The incidence of the root-sinus relationship in the group with $\mathrm{MSH}$ was $2.2 \%$, whereas it was $32.6 \%$ in the group without MSH. A statistically significant difference was found between these 2 groups (Table 2).

In the patients with $\mathrm{MSH}$ and the posterior teeth, the minimum distance of the root apex to the sinus base was found to be $5.98 \mathrm{~mm}$ on average. This value was $0.62 \mathrm{~mm}$ in the group without $\mathrm{MSH}$, but with the posterior teeth. The difference between these 2 values was statistically significant $(p=0.000)$ (Table 3$)$. 
Table 3. Statistical comparison of the average minimum distance between the root apices and the sinus, and the average minimum horizontal and vertical alveolar crest dimensions in hypoplastic and non-hypoplastic maxillary sinuses

\begin{tabular}{|c|c|c|c|c|c|c|c|c|c|}
\hline \multirow{2}{*}{ Measurement } & \multicolumn{4}{|c|}{ Hypoplastic maxillary sinuses } & \multicolumn{4}{|c|}{ Non-hypoplastic maxillary sinuses } & \multirow{2}{*}{$p$-value } \\
\hline & $n$ & $\min$ & $\max$ & $M \pm S D$ & $n$ & $\min$ & $\max$ & $M \pm S D$ & \\
\hline $\begin{array}{l}\text { Minimum distance between the root apex } \\
\text { and the maxillary sinus floor } \\
{[\mathrm{mm}]}\end{array}$ & 45 & 0 & 15.0 & $5.98 \pm 3.83$ & 43 & 0 & 7.5 & $0.62 \pm 1.42$ & $0.000^{*}$ \\
\hline $\begin{array}{l}\text { Minimum horizontal alveolar crest dimension }{ }^{b} \\
{[\mathrm{~mm}]}\end{array}$ & 24 & 2.8 & 8.5 & $5.17 \pm 1.87$ & 41 & 1.3 & 13.4 & $3.83 \pm 2.10$ & $0.002^{*}$ \\
\hline $\begin{array}{l}\text { Minimum vertical alveolar crest dimension }{ }^{\mathrm{b}} \\
{[\mathrm{mm}]}\end{array}$ & 24 & 4.0 & 19.5 & $12.47 \pm 3.94$ & 41 & 0.5 & 13.3 & $5.03 \pm 3.08$ & $0.000^{*}$ \\
\hline
\end{tabular}

$M$ - mean; SD - standard deviation; ${ }^{a}$ comparison between dentulous maxillary sinuses; ${ }^{b}$ comparison between edentulous maxillary sinuses; ${ }^{*}$ statistically significant; Mann-Whitney U-test.

The kappa value (inter-observer agreement) was 0.92 for the closest distance between the root apex and the sinus base.

\section{Comparison of the group with maxillary sinus hypoplasia without the posterior teeth and the group without maxillary sinus hypoplasia without the posterior teeth}

In the group with MSH without the posterior teeth, the minimum horizontal dimension of the alveolar crest was $5.17 \mathrm{~mm}$ on average. This value was found to be $3.83 \mathrm{~mm}$ in the group without MSH and without the posterior teeth. There was a statistically significant difference between these 2 values ( $p=0.002)$ (Table 3$)$. The kappa value (inter-observer agreement) was 0.87 for the minimum horizontal alveolar crest dimension.

In the patients with MSH without the posterior teeth, the minimum vertical dimension of the alveolar crest was found to be $12.47 \mathrm{~mm}$ on average. This value was $5.03 \mathrm{~mm}$ in the group without MSH and without the posterior teeth. There was a significant difference between these 2 values $(p=0.000)$ (Table 3$)$. The kappa value (interobserver agreement) was 0.87 for the minimum vertical alveolar crest dimension.

\section{Discussion}

The maxillary sinus is located between the nasal and oral cavities, so maxillary sinus diseases are most often caused by bacterial invasion. ${ }^{11}$ Root canal treatment, a tooth extraction or trauma may cause the bacteria of the dental area to pass into the maxillary sinus. When looking at the bacterial pathways leading to acute sinusitis, ${ }^{12}$ pathogenic bacteria have been observed in the oral cavity (Streptococcus pneumoniae, Haemophilus influenza and Moraxella catarrhalis). In the present study, the relationship between MSH and the root apices was compared with regard to normal sinuses, which has not been done before. The relationship between the maxillary sinus floor and the maxillary tooth root tips was greater in the patients without MSH than in the MSH patients. Moreover, the minimum distance between the root apex and the sinus floor was compared between the MSH group and the group without MSH. The minimum distance between the maxillary sinus floor and the maxillary tooth root tip was shorter in the patients without MHS than in the MSH patients. In other words, the sinuses in the MSH patients were farther away from the dental area. There have been studies reporting that chronic inflammation in the maxillary sinus has a dental origin in $14-24 \%$ of cases. ${ }^{13,14}$ Although not confirmed by other studies, the risk of sinus infections of dental origin was predicted to be lower in the case of MSH. The present study revealed that fewer complications are to be expected in posterior maxilla endodontic and surgical treatment of MSH patients due to a longer distance from the root apex to the sinus floor. Also, due to the sufficient amount of bone, this area might be regarded as a suitable autograft area.

Researchers have reported similar results of sinus infections in patients with MSH. Erdem et al. revealed a relationship between MSH and chronic maxillary sinusitis. ${ }^{15}$ They suggested that hypoplasia or an absent uncinate process may be the cause of sinusitis. ${ }^{15}$ Similarly, Milczuk et al. mentioned a relationship between MSH and chronic maxillary sinusitis in children. ${ }^{16}$ In our study, there was a lower prevalence of sinus pathology in the patients with MSH than in the control group, although the difference was not statistically significant.

Haller cells were first described by Albrecht von Haller in 1765 and alternatively named infraorbital ethmoid cells. These cells are mostly encountered as incidental findings during the CT examination of the paranasal sinuses. Haller cells develop into the floor of the orbit (the medial portion) and above the maxillary sinus ostium (the lateral portion). Although unilateral Haller cells are encountered frequently, bilateral Haller cells are rare. ${ }^{17,18}$ The presence of Haller cells is thought to be a basic factor in recurrent maxillary sinusitis, ${ }^{18,19}$ especially because various retrospective studies have shown a crucial correlation between the size of Haller cells (greater than $3 \mathrm{~mm}$ ) 
and maxillary sinusitis. ${ }^{16,20}$ In the present study, Haller cells were found considerably less often in the patients with MSH than in those with normal sinuses. According to our study, a low occurrence of Haller cells in the patients with MSH may be considered as a factor that reduces the likelihood of maxillary sinusitis as compared to the patients without MSH.

Although there are no studies in the literature investigating the direct effect of a sinus septum on maxillary sinus infections, the perforation of the maxillary sinus mucosa, which is one of the complications especially in implant surgery, is a highly serious situation. Studies have shown that the risk of perforation increases in the presence of a sinus septum and that the placement of graft material in the region is difficult. ${ }^{21}$ In our study, the incidence of a sinus septum in the patients with MSH was found to be statistically lower than in the patients without sinus hypoplasia, so it could be interpreted that it was safer in terms of perforation risk.

It is still controversial in the literature whether an elliptically shaped accessory ostium, ${ }^{22}$ which can be easily diagnosed during routine endoscopic nasal examinations, is congenital or acquired following acute maxillary sinusitis. ${ }^{23}$ This anatomic variation has been thought to play a role in the development of maxillary sinusitis. ${ }^{24}$ Some researchers have suggested that an accessory maxillary ostium develops as a result of maxillary sinusitis, since they have reported that the prevalence of an accessory maxillary ostium is higher in patients with infundibular narrowing or a maxillary sinus infection. ${ }^{25,26}$ In our study, the prevalence of an accessory ostium was significantly lower in the patients with MSH, which supports the idea that the risk of a sinus infection from an accessory ostium is lower than in non-MSH patients.

The required alveolar bone height for long-term implant prognosis should be a minimum of 10-12 $\mathrm{mm}$. Unfortunately, the alveolar bone height in posteriorly edentulous maxillae below the maxillary sinuses is often less than $10 \mathrm{~mm} .{ }^{27}$ Although there is no precise ratio provided, it has been observed that as the vertical height increases, the cumulative success rate of a dental implant increases in the long term (10-12 years). ${ }^{28}$ Some alternative methods are available to solve this problem, such as augmenting the maxillary bone, using zygomatic implants or using short implants (4-8-millimeter long). ${ }^{29}$ In our study, the mean minimum vertical alveolar bone height in the posterior maxillae with $\mathrm{MSH}$ was found to be $12.47 \mathrm{~mm}$, which was statistically significantly higher than in the patients without sinus hypoplasia. Additionally, the mean minimum horizontal alveolar bone dimension in the posterior maxillae with MSH was found to be statistically greater than in the patients without sinus hypoplasia. Clinically speaking, implant surgery can be safe in patients with posteriorly edentulous maxillae and MSH due to the vertical and horizontal bone dimensions, according to our study.

\section{Conclusions}

This study differs in some aspects from others in the literature. The results show that in the case of $\mathrm{MSH}$, endodontic and surgical treatment is less likely to cause complications due to a larger distance between the tooth apex and the sinus floor. Anatomical variations that can cause sinusitis, such as accessory ostia and Haller cells, were found to be less frequent in the MSH patients. Other anatomical variations, such as sinus septa, were found to be less frequent in MSH. For implant surgery, the bone mass was found to be higher in the posteriorly edentulous maxillae of the MSH patients, as the dimensions of the posterior alveolar vertical and horizontal bone proved to be greater in the case of MSH. Before a surgical procedure, clinicians should at least be aware of this anatomical change.

\section{ORCID iDs}

Numan Dedeoğlu (D https://orcid.org/0000-0003-0892-3654 Suayip Burak Duman (D) https://orcid.org/0000-0003-2552-0187

\section{References}

1. Peyneau PD, Oliveira LGT, Carneiro PMR, Manzi FR. Maxillary sinus disease of odontogenic origin. Dent Press Endod. 2013;3(2):80-83.

2. Thiagarajan B, Narashiman S. Hypoplasia of all paranasal sinuses: A case series and literature review. Otolaryngol Online J. 2012;2(2):20-25.

3. Kosko JR, Hall BE, Tunkel DE. Acquired maxillary sinus hypoplasia: A consequence of endoscopic sinus surgery? Laryngoscope. 1996;106(10):1210-1213.

4. Bassiouny A, Newlands WJ, Ali H, Zaki Y. Maxillary sinus hypoplasia and superior orbital fissure asymmetry. Laryngoscope. 1982;92(4):441-448.

5. Altun O, Duman SB, Bayrakdar IS, Yasa Y, Duman S, Yılmaz SG. Cone beam computed tomography imaging of superior semicircular canal morphology: A retrospective comparison of cleft lip/palate patients and normal controls. Acta Odontol Scand. 2018;76(4):247-252.

6. Demirel O, Kaya E, Üçok CÖ. Evaluation of mastoid pneumatization using cone-beam computed tomography. Oral Radiol. 2014;30:92-97.

7. Hanzelka T, Dusek J, Ocasek F, et al. Movement of the patient and the cone beam computed tomography scanner: Objectives and possible solutions. Oral Surg Oral Med Oral Pathol Oral Radiol. 2013;116(6):769-773.

8. Teymoortash A, Hamzei S, Murthum T, Eivazi B, Kureck I, Werner JA. Temporal bone imaging using digital volume tomography and computed tomography: A comparative cadaveric radiological study. Surg Radiol Anat. 2011;33(2):123-128.

9. Fakhran S, Alhilali L, Sreedher G, et al. Comparison of simulated cone beam computed tomography to conventional helical computed tomography for imaging of rhinosinusitis. Laryngoscope. 2014;124(9):2002-2006.

10. Sirikçi A, Bayazit Y, Gümüsburun E, Bayram M, Kanlikana M. A new approach to the classification of maxillary sinus hypoplasia with relevant clinical implications. Surg Radiol Anat. 2000;22(5-6):243-247.

11. Brook I. Sinusitis of odontogenic origin. Otolaryngol Head Neck Surg. 2006;135(3):349-355.

12. Nash D, Wald E. Sinusitis. Pediatr Rev. 2001;22:111-117.

13. Uvarov VM. Odontogenic Maxillary Sinusitis [in Russian]. Leningrad, Russia: Medgiz; 1962:34-39.

14. Shargorodsky AG. Inflammatory Diseases of the Maxillofacial Region and the Neck [in Russian]. Moscow, Russia: Medgiz; 1985:15-24.

15. Erdem T, Aktas D, Erdem G, Miman MC, Ozturan O. Maxillary sinus hypoplasia. Rhinology. 2002;40(3):150-153.

16. Milczuk HA, Dalley RW, Wessbacher FW, Richardson MA. Nasal and paranasal sinus anomalies in children with chronic sinusitis. Laryngoscope. 1993;103(3):247-252. 
17. Ahmad M, Khurana N, Jaberi J, Sampair C, Kuba RK. Prevalence of infraorbital ethmoid (Haller's) cells on panoramic radiographs. Oral Surg Oral Med Oral Pathol Oral Radiol Endod. 2006;101(5):658-661.

18. Kantarci M, Karasen RM, Alper F, Onbas O, Okur A, Karaman A. Remarkable anatomic variations in paranasal sinus region and their clinical importance. Eur J Radiol. 2004;50(3):296-302.

19. Stammberger H, Wolf $\mathrm{G}$. Headaches and sinus disease: The endoscopic approach. Ann Otol Rhinol Laryngol Suppl. 1988;134:3-23.

20. Bolger WE, Butzin CA, Parsons DS. Paranasal sinus bony anatomic variations and mucosal abnormalities: CT analysis for endoscopic sinus surgery. Laryngoscope. 1991;101(1 Pt 1):56-64.

21. Ulm CW, Solar P, Krennmair G, Matejka M, Watzek G. Incidence and suggested surgical management of septa in sinus-lift procedures. Int J Oral Maxillofac Implants. 1995;10(4):462-465.

22. Thiagarajan B. Advanced anatomy of lateral nasal wall: For the endoscopic sinus surgeon [Internet]. Version 12. Ent Scholar. 2012 Sep 19. https://entscholar.wordpress.com/article/advancedanatomy-of-lateral-nasal-wall/. Accessed on September 19, 2012.

23. Genc S, Ozcan M, Titiz A, Unal A. Development of maxillary accessory ostium following sinusitis in rabbits. Rhinology. 2008;46(2):121-124.

24. Yenigun A, Fazliogullari Z, Gun C, Uysal II, Nayman A, Karabulut AK. The effect of the presence of the accessory maxillary ostium on the maxillary sinus. Eur Arch Otorhinolaryngol. 2016;273(12):4315-4319.

25. Mladina R, Vuković K, Poje G. The two holes syndrome. Am J Rhinol Allergy. 2009;23(6):602-604.

26. Gutman $M$, Houser $\mathrm{S}$. latrogenic maxillary sinus recirculation and beyond. Ear Nose Throat J. 2003;82(1):61-63.

27. das Neves FD, Fones D, Bernardes SR, do Prado CJ, Neto AJ. Short implants - an analysis of longitudinal studies. Int J Oral Maxillofac Implants. 2006;21(1):86-93.

28. Ferrigno N, Laureti M, Fanali S. Dental implants placement in conjunction with osteotome sinus floor elevation: A 12-year life-table analysis from a prospective study on 588 ITI implants. Clin Oral Implants Res. 2006;17(2):194-205.

29. Esposito M, Barausse C, Pistilli R, Sammartino G, Grandi G, Felice P. Short implants versus bone augmentation for placing longer implants in atrophic maxillae: One-year post-loading results of a pilot randomised controlled trial. Eur J Oral Implantol. 2015;8(3):257-268. 